\title{
TERBINAFINE: OPTIMIZATION OF A LC METHOD FOR QUANTITATIVE ANALYSIS IN PHARMACEUTICAL FORMULATIONS AND ITS APPLICATION FOR A TABLET DISSOLUTION TEST
}

\author{
Monika P. Tagliari*, Gislaine Kuminek, Sílvia H. M. Borgmann, Charise D. Bertol e Simone G. Cardoso \\ Departamento de Ciências Farmacêuticas, Universidade Federal de Santa Catarina, Campus Universitário Trindade, B1. K, \\ 88040-900 Florianópolis - SC, Brasil \\ Hellen K. Stulzer \\ Departamento de Ciências Farmacêuticas, Universidade Estadual de Ponta Grossa, Campus Uvaranas, Av. General Carlos Cavalcanti, \\ 4748, 84030-900 Ponta Grossa - PR, Brasil
}

Recebido em 1/12/09; aceito em 25/3/10; publicado na web em 29/6/10

\begin{abstract}
A simple liquid chromatographic method was optimized for the quantitative determination of terbinafine in pharmaceutical hydroalcoholic solutions and tablets, and was also employed for a tablet dissolution test. The analysis was carried out using a RP-C 18 $(250 \mathrm{~mm} \times 4.6 \mathrm{~mm}, 5 \mu \mathrm{m})$ Vertical $^{\circledR}$ column, UV-Vis detection at $254 \mathrm{~nm}$, and a methanol-water (95:5, v/v) mobile phase at a flowrate of $1.2 \mathrm{~mL} \mathrm{~min}^{-1}$. Method validation investigated parameters such as linearity, precision, accuracy, robustness and specificity, which gave results within the acceptable range. The tablets dissolution was quite fast: $80 \%$ of the drug was dissolved within 15 min.
\end{abstract}

Keywords: terbinafine formulations; method validation; dissolution test.

\section{INTRODUCTION}

Terbinafine hydrochloride (TBF) (Figure 1), chemically known as (E)-N-(6,6-dimethyl-2-hepten-4-ynyl)-N-methyl-1-naphthalene methanamine hydrochloride, is an allylamine derivative with antifungal activity. TBF is a slightly water soluble drug, showing a solubility of $5.32 \mu \mathrm{g} \mathrm{mL} \mathrm{m}^{-1}$<smiles>CN(C/C=C/C#CC(C)(C)C)Cc1cccc2ccccc12</smiles>

Figure 1. The chemical structure of terbinafine hydrochloride

TBF affects dermatophytes and some yeast, it is used orally for the treatment of dermatophyte infections of the skin and nails. It is also applied to the skin in the occurrence of dermatophytoses, pityriasis versicolor, and cutaneous candidiasis occurrence or superficial fungal infections, like seborrheic dermatitis, tinea capitis, and onychomycosis especially for its short duration therapy. TBF is commercially available in the pharmaceutical forms of creams, gels, tablets, sprays and solutions..$^{2-4}$

There is an official method to quantify TBF raw material through titrimetry. ${ }^{5}$ However, TBF pharmaceutical formulations are not yet official in any pharmacopoeia. On the other hand, the literature describes several methods to quantify TBF raw material, like, non-aqueous titrimetry, voltametry, UV derivative, capillary electrophoresis and high performance liquid chromatography (HPLC). ${ }^{6-10}$ Also, TBF has been determined in biological fluids by HPLC technique and microbiological bioassays. ${ }^{11-15}$ Another HPLC method has been used to determine the drug in tablets and creams. ${ }^{16}$

However, there is a lack of information concerning both the

*e-mail: monikatag@gmail.com quantitation of TBF in pharmaceutical solution dosage forms and the dissolution test of TBF from tablet dosage forms.

Drug dissolution testing is an integral part of pharmaceutical development and routine quality control monitoring of drug release characteristics. The profiles, obtained from dissolution rate studies, have also been used in an attempt to characterize the in vivo behaviour of drugs with success. They have to be performed under precisely specified conditions (i.e., temperature, volume, and stirring rate) that mimic processes in the human gastrointestinal tract. ${ }^{17} \mathrm{TBF}$ is a poorly water soluble drug, so its dissolution is a critical parameter to be analyzed, especially from tablets, where there are excipients that could interfere with its release.

The method validation is necessary to quantify the TBF in pharmaceutical formulations and dissolution test because of the data that are generated, will only be trustworthy if the method used to generate the data is reliable.

In this way, an accurate, simple, reproducible, and sensitive liquid chromatographic method previously described, ${ }^{16}$ was applied with some modifications for TBF quantification in hydroalcoholic solution and tablet dosage forms. This work also aimed at the determination of TBF after a tablet dissolution test.

\section{EXPERIMENTAL}

\section{Chemicals}

The TBF reference standard with stated purity of $99.8 \%$ was obtained from Galena (São Paulo, Brazil). The TBF formulations (hydroalcoholic solutions and tablets with $1 \%$ and $250 \mathrm{mg}$ of TBF, respectively) analyzed were supplied by local drugstores. Ultrapure water was provided by a Milli-Q ${ }^{\circledR}$ purification system (Millipore, USA). Methanol of HPLC grade was purchased from Vetec ${ }^{\circledR}$. Other solvents and reagents used were of analytical grade.

\section{Preparation of stock standard solution}

A stock standard solution of $1000 \mu \mathrm{g} \mathrm{mL} \mathrm{mL}^{-1}$ was prepared by dissolving $25 \mathrm{mg}$ of TBF reference standard in $2 \mathrm{~mL}$ of methanol 
in a $25 \mathrm{~mL}$ volumetric flask. The volume was completed with the mobile phase.

\section{Preparation of sample solutions}

Amounts equivalent to $25 \mathrm{mg}$ of TBF from pharmaceutical solutions and tablets were quantitatively transferred to $25 \mathrm{~mL}$ volumetric flasks, diluted with $2 \mathrm{~mL}$ of methanol and the volume was completed with the mobile phase. The obtained solutions were stirred in an ultrasonic bath for $10 \mathrm{~min}$ and filtered through quantitative filter paper. Subsamples of these solutions were diluted with mobile phase to provide final concentrations of $150.0 \mu \mathrm{g} \mathrm{mL}^{-1}$. The samples were filtered through $0.45 \mu \mathrm{m}$ nylon membrane before injection in the HPLC.

\section{HPLC instrumentation and chromatographic conditions}

The HPLC analysis was performed on a Shimadzu LC-10A system (Kyoto, Japan) equipped with a LC-10AD pump, SPD-10AV UV detector (set at $254 \mathrm{~nm}$ ), SCL-10Avp controller unit, and the sample injection was performed via a Rheodyne 7125 valve with a $20 \mu \mathrm{L}$ loop. A reversed phase $\mathrm{C}_{18}$ Vertical $^{\circledR}$ column $(250 \mathrm{~mm} \times 4.6 \mathrm{~mm}$ i.d. $-5 \mu \mathrm{m})$ maintained at $40 \pm 1^{\circ} \mathrm{C}$ was employed. The mobile phase consisted of methanol and water $(95: 5 \mathrm{v} / \mathrm{v})$ and was eluted isocratically at a flow-rate of $1.2 \mathrm{~mL} \mathrm{~min}^{-1}$. The injection volume was $20 \mu \mathrm{L}$ for all standards and samples. The peak areas were integrated automatically by computer using a Shimadzu Class VP V 6.14 software program.

\section{Method validation}

The method validation was based on the International Conference on Harmonization guidelines Q2 (R1), ${ }^{18}$ for validation of analytical procedures. The parameters used were required for the assay of a dosage form: linearity, range, quantification and detection limits, accuracy, specificity and precision.

\section{Linearity and range}

The linearity response was assessed in the range of 20.0-200.0 $\mu \mathrm{g} \mathrm{mL} \mathrm{m}^{-1}$. Appropriate amounts of the stock solution were diluted with mobile phase to give concentrations of 20.0, 50.0, 100.0, 125.0, 150.0, 175.0 and $200.0 \mu \mathrm{g} \mathrm{mL}^{-1}$. On 3 different days each sample was injected in triplicate. The peak areas of the chromatograms were plotted against the concentrations of TBF to obtain the calibration curve. The 5 concentrations of the standard solutions were subjected to regression analysis by the least squares method to calculate calibration equation and correlation coefficient.

\section{Determination of limit of quantitation $(Q L)$ and limit of detection} $(D L)$

The QL and DL were based on the standard deviation of the response and the slope of the constructed calibration curve. The QL may be expressed as:

$$
Q L=\left(\frac{10 \sigma}{S}\right)
$$

and the DL was expressed by the following equation:

$$
D L=\left(\frac{3.3 \sigma}{S}\right)
$$

where $\sigma$ is the standard deviation of the response and $S$ is the slope of calibration curve.
Specificity

The specificity was evaluated by checking the absence of interference by the excipients which take part in the solution (medium chain triglycerides, polyethylene glycol, propylene glycol, water and alcohol) and tablet formulations (microcrystalline cellulose, crospovidone, anhydrous colloidal silica, magnesium stearate, talc and lactose). Their concentrations were determined based in Handbook of Pharmaceutical Excipients and calculated for medium weight content. ${ }^{19}$ Triplicate injections of each formulation were carried out.

\section{Precision}

The precision assay was determined by repeatability (intra-day) and intermediate precision (inter-day). The repeatability was evaluated by assaying 6 samples solutions of TBF from solution and tablet formulations $\left(150.0 \mu \mathrm{g} \mathrm{mL}^{-1}\right)$ during the same day, under the same experimental conditions. Intermediate precision was evaluated by assaying 3 samples solutions on another day. The peak areas were determined and compared. The precision was expressed as percentage of relative standard deviation (R.S.D.); results must be less than $2 \%$ R.S.D.

\section{Accuracy}

The accuracy of the developed method was evaluated by a recovering test. TBF sample solutions containing $75.0 \mu \mathrm{g} \mathrm{mL} \mathrm{m}^{-1}$ obtained from solution and tablet formulations were fortified with 3 known concentrations of reference standard at 3 different levels (Table 1). The recovery of added standard was determined in triplicate analysis and calculated taking by the formula:

$$
R \%=\left(\frac{F s-S t}{S s}\right) \times 100
$$

in which $R$ is the recovery, $F_{S}$ is the fortified solution, $S_{S}$ is the sample solution and $S_{T}$ is the standard solution.

Table 1. The recovery test performed for each formulation

\begin{tabular}{lcc}
\hline $\begin{array}{l}\text { Fortified solution } \\
(\mu \mathrm{g} \mathrm{mL}\end{array}$ & $\begin{array}{c}\text { Sample solution } \\
\left(\mu \mathrm{g} \mathrm{mL}^{-1}\right)\end{array}$ & $\begin{array}{c}\text { Standard solution } \\
(\mu \mathrm{g} \mathrm{mL})\end{array}$ \\
\hline 120.0 & 75.0 & 45.0 \\
150.0 & 75.0 & 75.0 \\
180.0 & 75.0 & 105.0 \\
\hline
\end{tabular}

${ }^{a}$ each fortified solution was done in triplicate

\section{Robustness}

The robustness of the method was determined by analyzing the same samples $\left(150 \mu \mathrm{g} \mathrm{mL}^{-1}\right)$ under a variety of conditions of the method parameters, such as: flow rate $\left(1.0,1.2\right.$ and $\left.1.4 \mathrm{~mL} \mathrm{~min}^{-1}\right)$, column temperature $\left(35 \pm 1,40 \pm 1\right.$ and $\left.45 \pm 1^{\circ} \mathrm{C}\right)$, and variations in the mobile phase composition (methanol:water 93:7, 95:5 and 97:3).

\section{Analysis of TBF pharmaceutical solutions and tablets}

For quantitation of TBF in the dosage forms, 20 tablets containing $250 \mathrm{mg}$ of TBF and 6 solution flasks containing $1 \%$ of TBF were separated. Aliquots of $25 \mathrm{mg}$ of TBF from each tested sample were transferred into individuals $25 \mathrm{~mL}$ volumetric flasks containing $10 \mathrm{~mL}$ of mobile phase, stirred in an ultrasonic bath for $10 \mathrm{~min}$ and diluted to volume with the same solvent, obtaining the final concentration of $1000 \mu \mathrm{g} \mathrm{mL} \mathrm{m}^{-1}$. Appropriate amounts of this solution were diluted with the mobile phase, yielding concentration of $150.0 \mu \mathrm{g} \mathrm{mL}^{-1}$. Aliquots of $20 \mu \mathrm{L}$ were injected for the analysis and the amount of drug in the solutions and tablets calculated against the respective reference standard. 


\section{Method application for a dissolution test of TBF tablets}

TBF tablet dissolution test was performed in a multibath $(n=$ 6) dissolution test system Varian (São Paulo, Brazil), in accordance with the United States Pharmacopoeia (USP) general methods..$^{20}$ The dissolution method was based on the FDA. ${ }^{21}$ The dissolution apparatus was used with paddles at $50 \mathrm{rpm}$ and bath temperature maintained at $37 \pm 0.5^{\circ} \mathrm{C}$. Five hundred millilitres of freshly prepared and degassed citrate buffer solution $\mathrm{pH} 3.0$ was used as the dissolution medium. Dissolution samples (10 mL) were collected at 10, 15, 20, 30 and $45 \mathrm{~min}$ and filtered through quantitative filter. Sample solutions of $2 \mathrm{~mL}$ were transferred into a $10 \mathrm{~mL}$ volumetric flask, the solution $\mathrm{pH}$ was corrected to 6.0 and diluted with mobile phase. The TBF standard solution $\left(100.0 \mu \mathrm{g} \mathrm{mL}^{-1}\right)$ was prepared in the same way. The solutions were filtered through $0.45 \mu \mathrm{m}$ membrane filter and the TBF quantification was performed by LC-method. The measured peak area of the test samples was compared with the peak area of the TBF standard. The amount of TBF in the tested samples was calculated as percentage dissolved.

\section{RESULTS AND DISCUSSION}

\section{Method validation}

Since TBF pharmacopoeial monographs are currently not available in any official compendia, the LC-method here employed was based on the previously validated method of Cardoso and Schapoval ${ }^{16}$ in which a HPLC method for the quantitation of TBF in pharmaceutical tablets and creams was developed and validated.

According to $\mathrm{ICH}$, revalidation may be necessary in the circumstances that there are changes in the composition of the finished product and/or in the analytical procedure. Besides, the degree of revalidation required depends on the nature of the changes. ${ }^{18}$ Therefore, the original method suffered some modifications because it was applied for a different purpose. In this work the main objective is to quantify TBF in pharmaceutical solutions and tablets, and to quantify the drug after a dissolution test of tablets. Besides, changes were made in HPLC system temperature, stationary phase, mobile phase flow rate, and equipment model which are important parameters that could interfere with the final results.

In accordance with Cardoso and Schapoval, ${ }^{16}$ the UV absorption spectrum of TBF had showed an intense absorption at $224 \mathrm{~nm}$, but the detection was monitored at $254 \mathrm{~nm}$ since it offered more selectivity.

The TBF retention time with the optimized method was about $6.0 \mathrm{~min}$.

The linearity of detector response was assessed of various solution standards over the range of $20.0-200.0 \mu \mathrm{g} \mathrm{mL}^{-1}$. The value of the determination coefficient calculated $\left(r^{2}=0.9997, y=16142 x-854\right.$; where, $\mathrm{x}$ is concentration and $\mathrm{y}$ is the peak absolute area) indicated the linearity of the calibration curve for the method. The validity of assay was verified by analysis of regression $\left(\mathrm{F}_{\text {calculated }}=8568.5>\right.$ $\mathrm{F}_{\text {critical }}=0.0001 ; \mathrm{P}=5 \%$ ).

The quantitation and the detection limits calculated were 2.7 and $0.9 \mu \mathrm{g} \mathrm{mL}^{-1}$ respectively, which indicate the adequate sensitivity of the method.

The specificity of the method was evaluated by analyzing samples of solutions and tablets without TBF (placebo). The chromatograms showed that the method is specific and there is no interference or overlaps of the excipients with the TBF response at $254 \mathrm{~nm}$ detection wavelength (Figure 2).

The repeatability (intra-day) and intermediate precision (interday) of the method were determined and the obtained results are reported in Table 2. All the data are within the acceptance criteria of
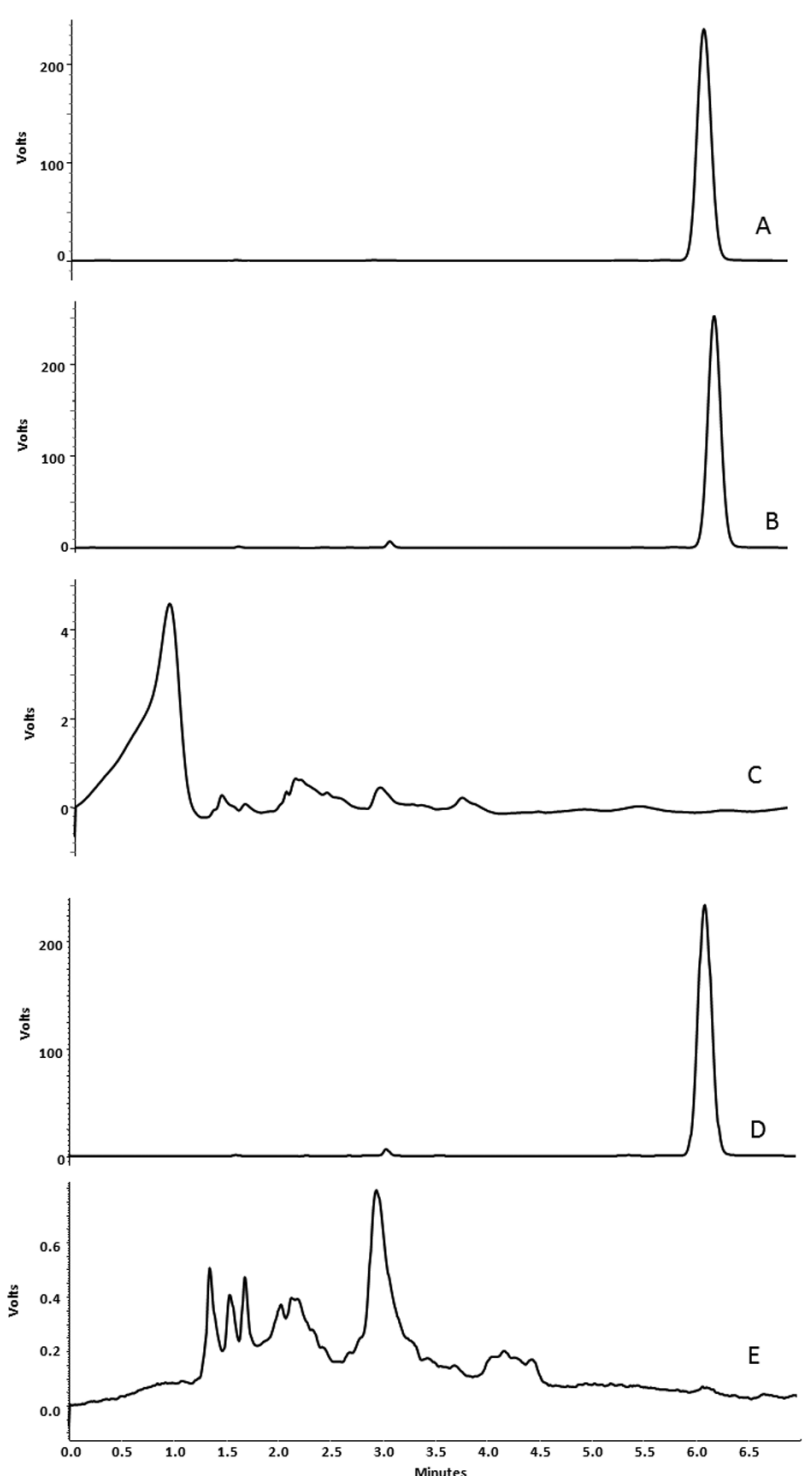

Figure 2. Representative chromatograms obtained under the experimental

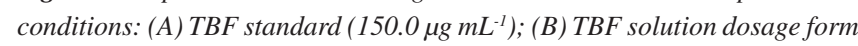

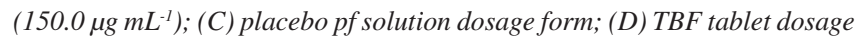
form (150.0 $\left.\mu \mathrm{g} \mathrm{mL} \mathrm{L}^{-1}\right)$, and (E) placebo of tablet dosage form

$2 \%$, which indicate acceptable precision. The amounts of TBF found on the analysis were equivalent $(\mathrm{P}<0.05)$.

The accuracy of the method was determined by the recovery test. The recovery percentage was calculated from the differences between the peak areas obtained from fortified and sample solutions. No significant differences were observed between amounts of TBF added and the amounts found $(\mathrm{P}<0.05)$. The obtained values were within the range of 98.0-103.0\% for solution and tablets, satisfying the acceptance criteria for the study (Table 2).

Robustness is defined as a measure of the method's capability to remain unaffected by small, but deliberate variations in method parameters. In this way, it was observed that the column temperature did not affect the drug elution. On the other hand, the mobile phase composition and flow rate resulted in changes in drug retention time (ranged from 5.2 to 6.9), because of these parameters are related with the time of interaction between drug and stationary phase. However, these small changes in retention time did not affect drug determination in the pharmaceutical formulations. 
Table 2. Results from determination of the intra- and inter-day precision, and the accuracy of the method.

\begin{tabular}{lcc}
\hline \multirow{2}{*}{ Precision } & \multicolumn{2}{c}{$\%$ Recovered $\pm \mathrm{RSD}^{\mathrm{b}}(\%)$} \\
\cline { 2 - 3 } Intra-day precision & TBF solutions & TBF tablets \\
$\mathrm{n}=6$ & $99.5 \pm 0.3$ & $101.7 \pm 0.5$ \\
Inter-day precision & & $102.1 \pm 1.5$ \\
$\mathrm{n}=3$ & $98.5 \pm 1.4$ & \\
\hline Accuracy $(n=3)$ & Recovery ${ }^{\mathrm{a}}(\%) \pm \% \mathrm{RSD}^{\mathrm{b}}$ \\
Fortified solution & $\mathrm{TBF}$ solutions & $\mathrm{TBF}_{\text {tablets }}$ \\
$\left(\mu \mathrm{g} \mathrm{mL}^{-1}\right)$ & $101.1 \pm 0.4$ & $99.8 \pm 0.5$ \\
120.0 & $102.3 \pm 0.2$ & $98.5 \pm 0.3$ \\
150.0 & $103.0 \pm 0.5$ & $99.2 \pm 0.3$ \\
180.0 & &
\end{tabular}

average value obtained from three experiments; ${ }^{\mathrm{b}} \mathrm{RSD}=$ Relative standard deviation.

\section{Analysis of TBF pharmaceutical solutions and tablets}

In accordance with the results previously described in this work, the method was successfully revalidated, demonstrating adequate linearity, specificity, precision, accuracy and robustness, and is suitable to quantify TBF in pharmaceutical solutions and tablets.

The quantitative assay of TBF in solution dosage form was within 99.2-99.8\%, while for tablet dosage form it was within 100.9-102.1\%.

\section{Dissolution test of TBF tablets}

Dissolution testing is an essential requirement for the development, establishment of in vitro dissolution and quality control of solid oral dosage forms.

The LC-method described was applied to quantify TBF in tablets, and the content value was used to correct the dissolution percentage of them.

The drug release profile, determined by the dissolution test at mentioned conditions is given in Figure 3. The results are expressed as TBF concentration dissolved versus time. The profile can be considered satisfactory. The dissolution is quite fast: $80 \%$ of the drug was dissolved within $15 \mathrm{~min}$ and the drug dissolution was concluded after $45 \mathrm{~min}$.

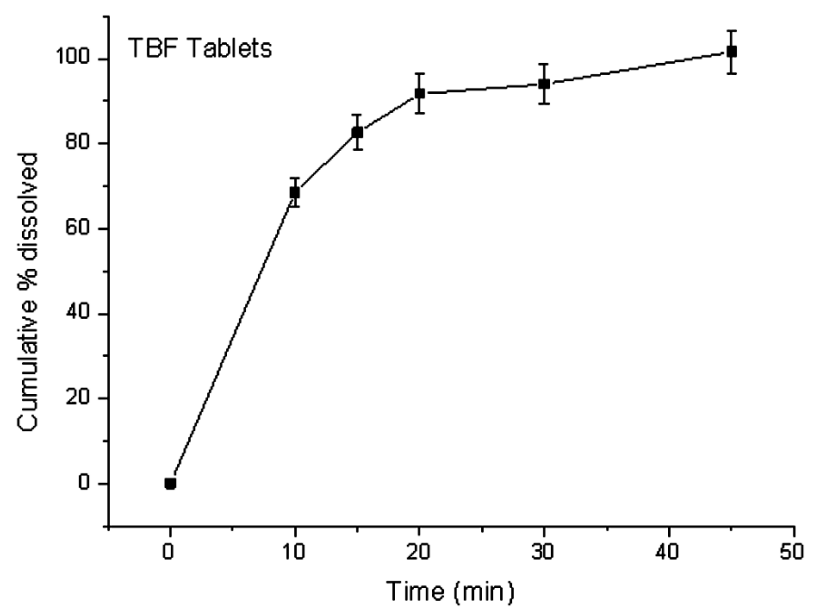

Figure 3. In vitro dissolution profile of TBF from tablet dosage form

\section{CONCLUSION}

A simple and efficient reversed-phase HPLC method was revalidated and found to be accurate, precise, robust and linear across the analytical range. The method was specific for the determination and quantification of TBF in solution and tablet dosage forms, and in dissolution samples. The method may be used to assess the quality of commercially available TBF pharmaceutical products.

\section{REFERENCES}

1. Hector, R. F.; Clinical Techn. Small Anim. Pract. 2005, 20, 240.

2. Evans, E. G.; Dodman B.; Williamson, D. M.; Brown, G. J.; Bowen, R. G.; Br. Medic. J. 1993, 307, 645.

3. Haugh, M.; Helou, S.; Boissel, J. P.; Cribier, B. J.; Br. J. Dermatol. 2002, 147, 118.

4. Matysová, L.; Solich, P.; Marek, P.; Havlíková, L.; Nováková, L.; Šícha, J.; Talanta 2006, 68, 713 .

5. European Pharmacopoeia, 2006, 6 ${ }^{\text {th }}$ ed., p. 2145.

6. Cardoso, S.; Schapoval, E. E. S.; J. AOAC Int. 1999, 82, 830.

7. Arranz, A.; Betoño, S. F.; Moreda, J. M.; Cid, A.; Arranz, J. F.; Anal. Chim. Acta 1997, 351, 97.

8. El-Saharty, Y. S.; Hassan, N. Y.; Metwally, F. H.; J. Pharm. Biomed. Anal. 2002, 28, 569.

9. Mikuš, P.; Valášková, I.; Havránek, E.; Talanta 2005, 65, 1031.

10. Rani, B. S.; Reddy, P. V.; Babu, G. S.; Sankar, G. G.; Rao, J. V. L. N. S.; Asian J. Chem. 2006, 18, 3154.

11. Dotsikas, Y.; Apostolou, C.; Kousoulos, C.; Tsatsou, G.; Loukas, Y. L.; Biomed. Chromatogr. 2007, 21, 201.

12. Kovarik, J.; Mueller, E. A.; Zehender, H.; Denouel, J.; Caplain, H.; Millerioux L.; Antimicrob. Agents Chemother. 1995, 39, 2738.

13. Denouël, J.; Keller, H. P.; Schaub, P.; Delaborde, C.; Humbert, H. J.; J. Chromatogr., B: Anal. Technol. Biomed. Life Sci. 1995, 663, 353.

14. Häusser, M.; Schmitt, M. J.; Bernard, E. M.; Armstrong, D.; Eur. J. Clin. Microbiol. Infect. Dis. 1988, 7, 531.

15. Kan, L.; Henderson, D. K.; Bennett, J. E.; Antimicrob. Agents Chemother. 1986, 30, 628.

16. Cardoso, S. G.; Schapoval, E. E. S.; J. Pharm. Biomed. Anal. 1999, 19, 809.

17. Savaser, A.; Goraler, S.; Tasoz, A.; Uslu, B.; Lingeman, H.; Ozkan, A. S.; Chromatographia 2007, 65, 259.

18. International Conference on Harmonization (ICH); Validation of Analytical Procedures: Text and Methodology, Q2 (R1), November 2005.

19. Rowe, R. C.; Sheskey, P. J.; Owen, S. C; Handbook of Pharmaceutical Excipients, $5^{\text {th }}$ ed., Pharmaceutical Press: Londres, 2006.

20. The United States Pharmacopeia (USP), 30 ${ }^{\text {th }}$ ed., United States Pharmacopoeial Convention: Rockville, 2007, p. 2288.

21. United States Food and Drug Administration, Center for Drug Evaluation and Research (CDER); Dissolution methods for drug products, Rockville, 1997. 